\title{
Time-use preference and adaptation in relational exchanges
}

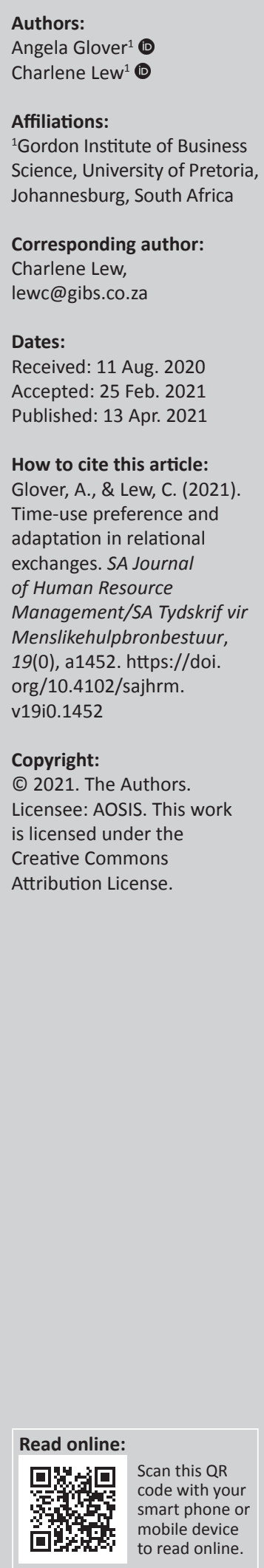

Orientation: Similarity of leaders and members encourage positive relational exchanges. However, the role of different time-use preferences, and how leaders and members adapt to the preferences of others in relational exchanges have not yet been studied.

Research Purpose: This research explores how time-use preference plays a role in the dyadic relationships between leaders and members within leader-member exchange (LMX) theory.

Motivation for the study: We argue that differences between the time-use preferences of leaders and team members result in relational adaptations.

Research approach/design and method: The qualitative research design employed semistructured interviews with nine leaders and 11 employees in a major retail bank in South Africa and data were analysed through thematic analysis.

Main findings: The research shows the nature of time-use preference in varying relational exchanges, discover how time-use preferences manifest and how leaders and members adapt to one another's preferences.

Contribution/value add: The study contributes to time-use preference literature by illustrating how polychronic and monochronic preferences may manifest in the workplace. Furthermore, we contribute to an understanding of the nature of relational exchanges in LMX theory by illustrating the influence of polychronicity on dyadic relationships and discuss how leaders and members adapt their preferences.

Practical/managerial implications: We propose a framework of the dynamics of time-use preference-based relational entrainment and provide practical considerations to help mitigate the negative impacts that differing preferences can have.

Keywords: leader-member adaptation; monochronicity; polychronicity; relational exchanges; time-use preference.

\section{Introduction}

It is well established that the quality of work relationships is an antecedent of positive organisational behaviour (Graen \& Uhl-Bien, 1995). Leader-member exchange (LMX) theory provides a basis for understanding how, through participating in varying forms of social exchanges, leaders and followers develop relationships, which affect how they treat each other (Dansereau, Graen, \& Haga, 1975; Martin, Guillaume, Thomas, Lee, \& Epitropaki, 2016). High quality LMX experiences positively relate to desirable work outcomes, such as improved task performance, organisational citizenship and reduction in turnover intentions (Martin, Thomas, Legood, \& Dello Russo, 2018). According to LMX differentiation theory similarity results in better exchanges and differences result in poorer exchanges in relationships.

As perceived similarity is a well-recognised antecedent of quality relational exchanges (Henderson, Liden, Glibkowski, \& Chaudhry, 2009; Murphy \& Ensher, 1999), exploration of differences in work preferences becomes significant. Work values dissimilarity can increase differentiation, creating challenges for leaders who must meet their demands for differing exchange interactions (Le Blanc \& González-Romá, 2012). Thus, the relationship between a leader and member, crucial to the cohesive fabric of the team, is influenced by differences or similarities in various individual preferences and behaviours.

An integral but often ignored dimension of individual preference and behaviour is time-use preference (Capdeferro, Romero, \& Barberà, 2014). Time-use preference influences how an individual manages his or her own time: the importance they place on punctuality, how firmly they adhere to deadlines and whether they like to complete tasks sequentially or work on 
many tasks simultaneously (Capdeferro et al., 2014). Working together in dyadic relationships, leaders and members with opposing time-use preferences may find each other's approaches frustrating or difficult to cope with (Schein, 1991).

\section{Research purpose and objectives}

The nature of time-use preference in leader-member relationships is not well understood; a need which was recognised more than a decade ago (Bluedorn \& Jaussi, 2008), but has still not been adequately addressed (Mittal \& Bienstock, 2020). Individuals perceive and manage time through differing lenses, which impacts the way they conduct themselves at work and approach tasks. It may also affect their relationship with others, particularly between leaders and members (Bluedorn \& Jaussi, 2008).

Leader-member relationships are a crucial enabler to bigger organisational success, as individual performance is reliant on high-quality LMXs (Tanskanen, Mäkelä, \& Viitala, 2019). Underlying concealed differences that are tacit and not confronted, such as time-use preference, can create tension and negatively impact a working relationship.

This leaves us with the question of how expressed time-use preference differences play out in LMXs. Specifically, how do they manifest, what is their impact on individuals and relationships and how do individuals change their behaviour to adapt to such differences?

The aim of this work is to explore the role of time-use preference and adaptation in relational exchanges. We build propositions that time-use preferences are recognisably different between individuals within organisations and that this helps to inform the quality of relationships and interpersonal adaptation.

\section{Literature review}

\section{Time-use preference}

The framework of polychronicity versus monochronicity is of value to this study. The polychronicity concept was first identified as a factor influencing behaviour by Hall (1977). Hall (1977) defined monochronicity as an importance placed on schedules, deadlines, plans and punctuality. In contrast, polychronic individuals prioritise interpersonal relationships over the arbitrariness of linear time and prefer to combine multiple tasks simultaneously, not objecting to interruptions. Other early descriptions of polychronicity referred to the importance of control and efficient use of time (Macan, Shahani, Dipboye, \& Phillips, 1990), the passing of time awareness (Landy, Rastegary, Thayer, \& Colvin, 1991) and temporal depth that indicate the time horizons considered when thinking of the past and future (Bluedorn, 2002).

Individual differences in time-use preference referred to the pattern of time-use and urgency of work completion, specifically as it pertained to how a culture understands time and the preferred temporal pattern of behaviour (Conte, Rizzuto, \& Steiner, 1999). These researchers found that polychronic individuals are achievement-oriented and impatient and have more fluid time awareness, for instance as seen in the French culture (Conte et al., 1999). This differs from Hofstede's and Minkov (2010) supposition that longterm oriented cultures focus their efforts on future rather than the past and focus efforts on frugality, hard work and persistence.

More recent expansions on the definition characterised polychronic individuals as multitaskers who prefer to be involved in many projects or operations simultaneously, whilst monochronic individuals prefer to work linearly on sequential tasks, focusing on one thing at a time. Poposki and Oswald (2010) defined polychronicity as 'an individual's preference for shifting attention amongst ongoing tasks, rather than focusing on one task until completion and then switching to another task' (Poposki \& Oswald, 2010, p. 250). This indicates that polychronicity may be a 'trait-like preference' (Kirchberg, Roe, \& Van Eerde, 2015, p. 114). Nowack (2016) added psychological time to the definition, showing the significance of perception of the reality of time.

Polychronicity stems from 'three non-mutually exclusive dimensions that illuminate the differences between polychronic and monochronic people: tangibility, involvement and scheduling' (Capdeferro et al., 2014, p. 306). Therefore, a monochronic individual will prefer subdivided schedules for precise use of time and punctuality (tangibility), participation in one task at a time without interruption (involvement) and inflexibility regarding plans (scheduling) in order to make best use of the scarce resource of time. A polychronic individual prefers closer relationships to people over tasks, to be involved in several activities at one time and fluid planning (Capdeferro et al., 2014).

Beyond individual preference, certain environments are also more suitable to monochronic or polychronic tendencies, for instance, a fast-paced environment dealing with complexity and ambiguity and a need to manage multiple stakeholders is described as a polychronic environment (Schein, 1991). Persing (1999) suggested that engineers and scientists prefer monochronic environments with fewer interferences, but that creative individuals align better with polychronicity. Polychronicity has been found to be positively correlated to performance in environments where juggling multiple tasks simultaneously is a requirement. This included diverse jobs in the telecommunication industry (Kantrowitz, Grelle, Beaty, \& Wolf, 2012). The nature of the work environment of sales executives requires them to have polychronic preferences to thrive (Fournier, Weeks, Blocker, \& Chonko, 2013).

Organisations need a shared expectation of time, if only to co-ordinate activities within and between teams (HampdenTurner \& Trompenaars, 2011). Time-use preferences hold implications for perceiving similarity between individuals in 
the organisation and implicitly the quality of their exchanges. An exploration of how leaders and members experience these time preferences was therefore needed. Bluedorn and Jaussi (2008) for instance called for research on polychronicity specifically as a role-player in relationships between leaders and followers. Dille, Söderlund and Clegg (2018) argued that organisations involved in complex projects need to constantly assimilate divergent time preferences to overcome tensions of competing demands.

\section{Leader-member exchange}

Individual differences affect the quality of relational exchanges in organisations, as premised within LMX theory. Leadermember exchange theory focuses on the dyadic relationships between leaders and followers. The core concept of this theory is that the dyadic relationships that leaders develop with their members differ in quality and type as a result of the varying social exchanges that occur between them (Graen \& Uhl-Bien, 1995; Martin et al., 2018).

First developed by Dansereau et al. (1975), the theory asserts that leaders divide members into two groups: the in-group and the out-group. Members of the in-group experience highquality interactions with the leader and a relationship built on respect and mutual trust. Trust is an inextricable characteristic of a high-quality LMX relationship (Dirks \& Ferrin, 2002). Members of the out-group display opposing characteristics: low quality interactions with the leader and low trust (Graen \& Uhl-Bien, 1995). It therefore follows that being part of the in-group is more desirable than being part of the out-group and members can benefit from knowing which behaviours to strive for to land in the most desired group.

Attitudinal similarity leads to better relational exchanges between managers and members (Henderson et al., 2009). In addition, perceived similarities play a greater role in positive leader-member relationships than real demographic similarities (Murphy \& Ensher, 1999). Leaders and members exchange currencies such as extra-role contribution, affective engagement, demonstration of loyalty and respect (Liden \& Maslyn, 1998).

Even though similarity between a leader and team member has a strong influence on the quality of relationships (Henderson et al., 2009), there are many more personal and interpersonal factors that impact the development of quality relational exchanges (Dulebohn, Bommer, Liden, Brouer, \& Ferris, 2012). Different attachment styles such as the predisposition to be anxious, secure or avoidant in relationships, sometimes affect the relational quality too (Fein, Benea, Idzadikhah, \& Tziner, 2020).

This research concerns the notion of exchanges in as far as we explore the role of different time-use preferences in the relational exchanges. We propose that differences in time-use preference manifest within teams, and that individuals are able to identify characteristics betraying these dissimilarities within their peers, leaders and members. It is therefore important to understand how these differences manifest.

The process of LMX differentiation (Liden, Erdogan, Wayne, \& Sparrowe, 2006) refers to the varying ranges of LMX within a group, and the informal, often unconscious, processes undergone to distinguish between members and classify them into an in-group and an out-group, or into a range of differing quality LMX relationships (Martin et al., 2018).

The mechanism of differentiation falls outside the scope of this study. However, we recognise that individual characteristics of leaders, individuals and team members, such as their time preferences and their behavioural characteristics may affect the LMX differentiation process as intangible factors. Therefore, building an understanding of how people adapt to differing time-use preferences could lay a foundation for future research in the role of intangible factors in exchange differentiation. In this study, finding differences in time-use preference may offer an additional key to why differentiation takes place.

\section{Entrainment}

Following from our proposition that time-use differences affect relational exchanges, we propose that leaders and members will adapt their own behaviours to meet the timeuse preferences of the other. This may be explained through the concept of entrainment or the synchronisation of pace or cycle of activity, adjusted to match the pace or cycle of another activity (Bluedorn \& Jaussi, 2008). Entrainment pertains to individuals adjusting their own behaviours to meet the rhythms of others. In a dyadic relationship, entrainment may take place at an emotional level and a social level (Cropanzano, Dasborough, \& Weiss, 2017). When two rhythmic activities interact, they may become coherent, creating a single, ordered and stable rhythm. This manifests as alignment between time, pace, rhythm and cycles in organisational behaviour (Sandra \& Nandram, 2017). The aim of entrainment is to synchronise or align the temporal components of activities in a system and in relationships (Agndal \& Nilsson, 2019).

Yet, organisations are characterised by diversity of members' traits, skills, competencies, behaviours and preferences (Harvey, 2015). Consequently, individuals often need to align conflicting behaviours and preferences to collaborate successfully (Van Dick, Van Knippenberg, Hägele, Guillaume, \& Brodbeck, 2008). We therefore propose that because of organisational entrainment, individuals may adapt their time-use behaviour to meet one another's preferences and needs when working together. The exploration of time-use preference as a facet of relational exchanges becomes a vital new exploration to understanding how individual differences impact the complex dynamics thereof.

From the literature reviewed we proposed that leaders and members are aware of their differences in time-use preferences - this leads to differentiation of exchanges amongst leaders and members and individuals will adapt 
to one another's time-use preferences. To this end, we investigate three research questions:

Q1: How do time-use preference differences manifest?

Q2: What is the experience of time-use preference in dyadic leader-member relationships?

Q3: How do individuals adapt their time-use behaviours in the workplace?

\section{Research design \\ Research approach and philosophy}

We adopted an interpretivist philosophy with qualitative design (Glaser \& Strauss, 2009) to study time-use preferences in dyadic relationships through an inductive semi-structured interview approach, to build on an underexplored area of human preferences and behaviours.

\section{Population and sample}

To control for organisation-specific factors and an in-depth investigation (Eisenhardt \& Graebner, 2007), the research was conducted amongst leaders and members in a single product house in a financial institution. The unit represents multiple work types through customer service, operations, finance, compliance and marketing. Through nonprobability purposive sampling, we ensured diversity of time-use preference, job type and work experience. Nine leaders and 11 employees were selected. The 19 interviews represented 11 dyadic case studies. Adequate representation was ensured by including multiple ranges of experience and responsibilities in the sample (see Table 1a and Table $1 b$ ).

\begin{tabular}{lllll}
$\begin{array}{lllll}\text { TABLE 1a: Leader and member } \\
\text { Leference code } \\
\text { referenographics. }\end{array}$ & $\begin{array}{l}\text { Tenure as } \\
\text { manager }\end{array}$ & $\begin{array}{l}\text { Number of } \\
\text { direct reports }\end{array}$ & $\begin{array}{l}\text { Indicated time-use } \\
\text { preference }\end{array}$ & Gender \\
\hline L01 & 18 months & 3 & Monochronic & Male \\
L02 & 8 months & 4 & Polychronic/flexible & Female \\
L03 & 18 years & 4 & Polychronic & Female \\
L04 & 7 years & 7 & Monochronic/flexible & Male \\
L05 & 5 years & 3 & Monochronic & Female \\
L06 & 12 years & 8 & Monochronic/flexible & Male \\
L07 & 7 years & 7 & Monochronic/flexible & Male \\
L08 & 13 years & 6 & Monochronic & Male \\
L09 & 9 years & 13 & Monochronic & Female \\
\hline
\end{tabular}

\begin{tabular}{lllll}
\multicolumn{2}{l}{ TABLE 1b: Leader and member demographics. } \\
\hline $\begin{array}{l}\text { Member } \\
\text { reference code }\end{array}$ & $\begin{array}{l}\text { Tenure with } \\
\text { current manager }\end{array}$ & $\begin{array}{l}\text { Manager of } \\
\text { own team }\end{array}$ & $\begin{array}{l}\text { Indicated time-use } \\
\text { preference }\end{array}$ & Gender \\
\hline M01 & 6 months & Yes & Polychronic & Female \\
M02 & 2 years 6 months & No & Monochronic & Male \\
M03 & 4 years & Yes & Polychronic/flexible & Male \\
M04 & 1 year & No & Polychronic/flexible & Female \\
M05 & 4 years & Yes & Monochronic & Female \\
M06 & 2 years & Yes & Polychronic & Male \\
M07 & 3 years & Yes & Monochronic & Female \\
M08 & 1 year 2 months & No & Monochronic & Male \\
M09 & 2 years & Yes & Polychronic & Female \\
M10 & 4 years & Yes & Polychronic & Female \\
M11 & 1 year 6 months & Yes & Monochronic & Male \\
\hline
\end{tabular}

\section{Research setting}

The research was undertaken within a major retail bank in South Africa in 2019. The bank has been operating for over 180 years and employs approximately 40000 people. The bank is known as an innovator with an owner-manager culture and comprises of a diverse workforce. Employees deal with varying levels of complexity in an often fast-paced environment, with complex demands and multiple stakeholders.

\section{Data collection}

The first author held semi-structured face-to-face interviews with each participant over a 6 -week period, aligning to a cross-sectional approach (Creswell \& Creswell, 2017). The interviews continued until data saturation was reached and concepts were adequately explained.

The interview guide covered three themes: (1) manifestation of time-use preferences, (2) impact thereof on relationships and (3) adaptation to differences in time-use preferences. Section one focused on the respondent's own timeuse preference and behaviour (polychronicity versus monochronicity) based on the inventory of polychronic values (IPV) (Bluedorn, Kalliath, Strube, \& Martin, 1999). Section two examined the relationships between leaders and members, asking participants to describe the time-use preference of their leader or member and the quality of the dyadic relationship between them. Section three questioned the adaptions and behavioural shifts experienced by asking what adaptations the respondent may have made to adapt to a leader or member, as well as what adaptations they had observed in a leader, member or peer making to adapt to others.

The interviewer also asked participants to base their responses on their behaviour in the workplace, and then to compare and contrast it to their behaviour in their personal lives and allowed further open-ended reflection (Johnson, 2017).

\section{Data analysis}

After recording and transcribing the interviews, 86 codes were through an inductive approach (Bryant \& Charmaz, 2019) linked to literature. Codes, categories and themes were identified through thematic analysis (Braun \& Clarke, 2006) by using Atlas-ti software. Coding commenced during the interview process and codes were continually compared during the analysis. The coding process continued until after theoretical saturation was attained.

Member interviews increased the rate of addition of new codes, thus validating the inclusion of members into the sample and allowing for comparison with leaders' perspectives. In addition, the responses from members could be compared with those of the leaders, by using the same codes to describe aspects from differing perspectives. Adaptations of leaders and members were coded, respectively, as 'adapt to leader' and 'adapt to member'. The resultant 


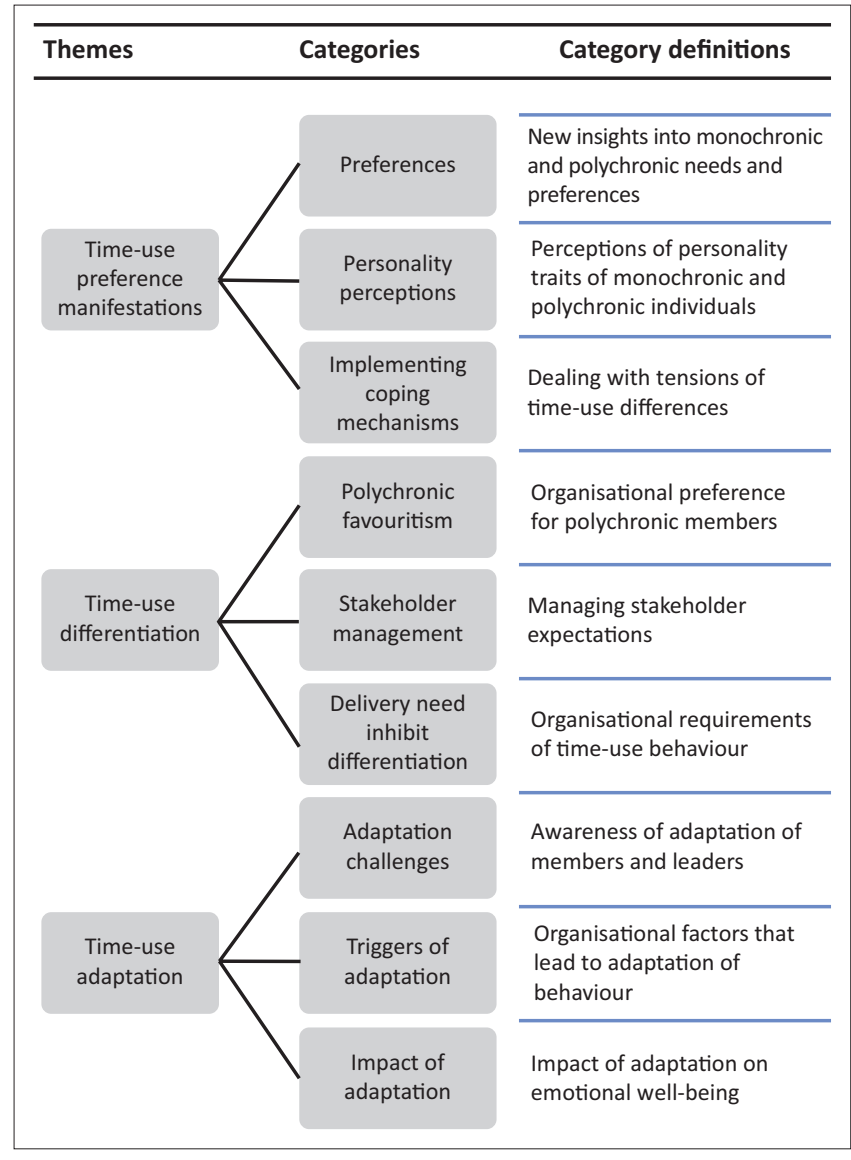

FIGURE 1: Data themes, categories and category definitions.

86 codes covered 958 quotes, with no code containing less than three quotations. Nine code categories were created through clustering (Gibbs, 2018). These categories were then further grouped to answer the three themes (see Figure 1).

\section{Data quality and integrity}

We implemented several methods to ensure appropriate rigour, validity and reliability in the iterative, qualitative process. In the research design phase, we ensured reliable results through a carefully designed interview guide, pilot study and prior discussion of methodology with research colleagues. We addressed transferability by formulating questions from a standardised interview protocol with prompts. Including interviewees of varying tenure strengthened the confirmability of the results. For generalisability, saturation was ensured (Gibbs, 2018).

We mitigated observer error and bias by recording and transcribing the interviews before commencing analysis (Saunders \& Lewis, 2017). In the analysis itself, we ensured valid findings by seeking any disconfirming evidence within the data after the primary themes were identified. Small pockets of disconfirming evidence were found, and these were retained in the findings when weighed against the confirming evidence (Creswell \& Miller, 2000). The use of transparent coding systems and codebook enabled inter-rate reliability for generalisability (Morse, 2015).

\section{Findings}

Considering the research aim to explore the role of timeuse preference and adaption in relational exchanges, three themes emerged relating to the manifestation of time-use preferences within teams, the impact of temporal behaviour on the individual and on the dyadic relationship and the adaptations of leaders and members to manage the tensions generated by time-use preference differences.

\section{Theme 1: Manifestations of time-use preference}

The findings show that time-use preferences manifest in numerous ways in the workplace, which can be identified and articulated between peers and within the dyadic leadermember relationship. These manifestations can be in the form of diverging preferences and behaviours, where individuals are forced to behave in ways that differ from their natural preferences.

\section{Time-use preferences and behaviours}

The findings confirm differing manifestations of time-use preferences within teams. In this study, team members who have worked together understand each other's time-use preferences (Conte et al., 1999), especially where individuals with strongly opposing preferences must work together. One member with strongly polychronic preferences said this about her monochronic peer:

' $[H]$ e likes to zone out, focus on one thing. That's the kind of person that he is. Even when he is sitting with the team, nine times out of ten, he will have his headphones on. He doesn't want to be bothered. We call it closing the door.' (Member 10, Polychronic, Female)

The same polychronic member described a different colleague who also has a monochronic preference, in a similar manner:

'[S]he gets a bit flustered if you sort of go to her and you disturb her. So, you need to leave her alone. She is not the kind of person who will juggle multiple things at the same time.' (Member 10, Polychronic, Female)

Members also notice the time-use behaviours of their leaders. One monochronic member observed the challenge that arises from opposing preferences to his direct line manager:

'[S]he is very much very structured, and she is able to juggle and multitask on a number of different things. And I think sometimes there's a bit of a disconnect between the two of us in that she will maybe want something and I will say to her no, look, I will get to it, but I just want to do it right.' (Member 08, Monochronic, Male)

The findings show that the context did not support monochronic preferences. Many respondents, despite their indicated monochronic preference, shared how their workplace behaviour was often pushed into a polychronic 
direction because of constant, competing demands. Similarly, Schein (1991) observed business contexts more suited to polychronics. One leader described the contrast by saying:

' $[I]$ allow the office to dictate multiple projects to happen at the same time, but at home I do prefer to have fewer projects that I do for a dedicated amount of time.' (L07, Monochronic/flexible, Male)

\section{Another monochronic member said:}

'[I]deally it would be nice to complete something, a project in a day, but unfortunately, we do complete parts of everything, but ultimately, it's to deliver the entire thing, if you get what I am saying, because we have to multitask.' (L09, Monochronic, Female)

Those with polychronic preferences indicated that they thrived under such circumstances. One member described being more productive as a result:

'[I] like to have a few things going on at the same time because, for me, if I just have one thing to work with, I tend to get a bit bored with it, or I take longer if it's one thing, whereas if it's many things, it forces me to do a lot more.' (M09, Polychronic, Female)

This distinction between preference and behaviour shows that there is in fact a necessity to use one's time in a certain manner (in this context, polychronically), which is similar to extant literature (Adams \& Van Eerde, 2010). However, it is this distinction that manifests differences in behaviour amongst peers and within the dyadic leader-member relationship.

\section{Associations with individual-specific attributes}

The findings show that individuals tend to link some personal attributes with polychronicity. For instance, some mentioned that women are more prone to polychronicity because of their roles as mothers, which often requires an ability to multitask. Others made the connection to introversion and extroversion, describing the more polychronic team members as extroverts, whilst the introverts displayed monochronic tendencies. This aligns to extant literature on polychronicity being a personality trait (Conte \& Gintoft, 2005; Kirchberg, Roe, \& Van Eerde, 2015). Personality type was used frequently by respondents to describe characteristics of their members and peers, with some incorporating time-use preference into their conceptualisation of personality.

'[I] think also because of my personality, I cannot work in an environment where there is absolute silence. I get very distracted; I think of a million things.' (M10, Polychronic, Female)

It would appear that insight into personality and time-use preference can improve the quality of relationships in the workplace.

\section{Individual coping mechanisms}

Literature suggests that monochronic individuals prefer not to be interrupted and to work on tasks sequentially and may structure their time to allow them space to do so (Capdeferro et al., 2014). However, the findings show that the environment may require them to manage multiple tasks simultaneously.
The monochronic interviewees described developing coping mechanisms, learning to be flexible and shifting their mindsets, as well as prioritising their tasks and relying on collaboration with their teammates to maintain delivery.

One monochronic deals with polychronic work demands and tensions by structuring his time:

' $[I]$ have a particular routine that I follow ... even though we are not required to use the spreadsheets, I still use it because that's what works for me.' (M02, Monochronic, Male)

Polychronics thrive on interruptions of their work flow and may become bored if undisturbed or unchallenged for too long, for instance, a polychronic said:

' $[I]$ 'm actually very happy to stop, it, it's almost like a breather for me. Because with every interaction for me, it's an opportunity to learn. It's an opportunity to get creative ... So, when somebody interrupts me, it's an opportunity. I am brainstorming at the same time just by the engagement that I am having.' (M10, Polychronic, Female)

Conversely, monochronic individuals find that disturbances interrupt the flow of their thought, especially during complex tasks. They strive to create the space to be uninterrupted, for instance through remote work or seeking the silence of early morning hours. According to one monochromic:

'[I] don't want to be interrupted because I want to think.' (M05, Monochronic, Female)

This presents new findings that time-use preferences manifest as attributes, which are visible to colleagues.

\section{Theme 2: Impact on relationships and individuals}

The findings show that different time-use preferences impact the dyadic relationship between members and leaders, with leaders preferring polychronic team members.

\section{Dyadic relationship aspects and differentiation}

Polychronic members in this study are perceived as being more easy-going and adaptable to change and require less investment of time from their manager, according to the findings. Those with a strong monochronic preference were viewed as resistant to change or unable to cope with the demands of the environment, which requires more time investment from the leaders. One leader described the differentiation in his team like this:

'[T] he ones that are more one-task aligned, I will actually give them more support and more guidance in how to go about doing it. The ones that can do multiple, I'm a little bit more relaxed on them, reason being I know the person that is used to one task finds it a bit difficult to handle multiple, so to support and to guide them and to suggest how to handle more than one task, and to make the best use of their time.' (L04, Monochronic/flexible, Male)

At the dyadic level, the similarities or dissimilarities between leaders and members form the foundation of the relationship 
(Murphy \& Ensher, 1999). Closer relationships may result from similarities. One leader said:

'[Y]ou tend to gravitate to people who actually have got commonalities with you.' (L05, Monochronic, Female)

The study found that the trust built over time between a leader and a member is vital to a good relationship. One leader described the trust he places in his subordinates:

' $[W]$ e have this level of understanding that she does her work in her own fashion and her own time. And I don't have to concern about what she's doing and how she's doing it. And we have sort of gone to that level of trust and that openness and trust.' (L07, Monochronic/flexible, Male)

The findings show that this trust and a common understanding of expectations also allows members to work independently of their leaders in terms of time frames of delivery of tasks. This allows the members to revert to their preferences without the constant influence of their leader. One leader described a trusted monochronic member's behaviour as follows :

'[N]ow he would come in the morning, make sure he clears his queue before he takes on new things, so that he can still apply his preference to some extent, so that it's not so hard for him during the day. So I see that he has actually found that method to help him quite a bit.' (L04, Monochronic/flexible, Male)

The findings show that building a quality relationship with a leader gives a member the space to behave in their preferred time-use manner.

\section{Managing upwards and downwards}

Investigating the mutual understanding of each others' timeuse preferences, the findings show that many participants were able to describe their manager's preferences accurately in line with the managers' own perceptions of their preferences (Conte et al., 1999). However, regardless of preference, all indicated that managers exhibited polychronic behaviours because of environmental and role demands. One member said the following about a leader's work preferences:

' $[L]$ ots of things at once. And I think, with him ... it can change as well. So, like today, he may think, okay, he wants to do it this way, but then tomorrow he will kind of have a brainwave. No, no, no, no, no. I think we should do it another way around.' (M09, Polychronic, Female)

Members described the pressure leaders faced within the organisation to conform to the time-use demands associated with that office:

' $[I]$ don't think you can be flexible in that level ... I think he is more like from his level, there are certain things that you must just fall in.' (M01, Polychronic, Female)

This behaviour necessitated members to pre-empt their leaders' needs to prevent being caught on the back foot. The constant juggling of tasks by both leader and member meant that there could be confusion about expectations, necessitating tight management of stakeholders and deliverables to align priorities and allocation of resources. In addition, members needed to set boundaries to prevent work impeding into their personal time or planned work activities. One leader described the boundaries that a monochronic member has set for herself:

'[S] he likes doing one thing at a time. She is very clear about it. She is got very clear boundaries about what things she is doing and how often she does them.' (L07, Monochronic/flexible, Male)

Many leaders were able to recognise the different preferences of their team members in the same way that they were able to recognise their individual strengths and weaknesses. Some leaders valued the heterogeneity within their teams, specifically if the diversity of time-use preference was able to lend itself to a more cohesive team dynamic. One leader said:

' $[M]$ y focus would be less on working like me or a set time type of thing, I will let you to find a flow to know what works for you. But making sure that it works within the overall flow of what we are trying to achieve as a team and if it does not work with the overall flow, that for me is more of a problem in itself.' (L02, Polychronic/flexible, Female)

\section{The continuous need to deliver}

Within the study's context, the need to perform and deliver to deadlines overrode any individual time-use preferences. This high-pressure environment seems to drive polychronic behaviour, as alluded to earlier, as polychronics perform better under these circumstances (Kantrowitz et al., 2012). This means that an inability of a member to adapt to the polychronic requirements becomes more noticeable to a leader:

'[Y]ou will be able to see from a poor-quality report that this person could not juggle.' (L09, Monochronic, Female)

Individuals who found it difficult to adapt to the pace of the environment and polychronic demands seemed more conspicuous to the interviewed leaders, drawing more attention to their own behaviour. The tension between delivering quantity and quality began to emerge, as monochronic members referred to a desire to spend more time on tasks to be able to deliver a quality output, whilst the environment demanded quantity and deadline-adherence instead. Leaders valued the ability of members to overcome their own preferences to meet required outputs and deadlines:

' $[I]$ think the key is also to be agile enough to be able to be, not to be dead-set in terms of "I prefer this," "this is how I like working," because when things need to be done, you need to chip in, come in, do what you need to do, move on to the next.' (L05, Monochronic, Female)

According to the findings, leaders play a vital role in encouraging and guiding their members to be able to perform tasks outside of their comfort zones, whilst peers provide support.

\section{Theme 3: Adaptations to time-use preference differences}

Where time-use preferences differ between individuals and a working relationship is required, individuals must adjust 
their behaviour to be able to synergise through entrainment (Cropanzano et al., 2017). We found that individuals do, in fact, adjust their behaviour according to the time-use preference of their leaders and members, as well as the demands of the environment. We also identified some of the factors that drive these changes, as well as the impact these changes have on individuals.

\section{Behavioural adaptations to adjust to the time-use preferences of others}

Most of the respondents gave examples of how they adjust their behaviour. One member said:

'[Y]ou need to change. You know, our business is changing. We want to remain relevant. So, there are things that we need to do to adapt to what the business requires.' (M04, Polychronic/flexible, Female)

There was a mixed response to questions regarding who should adapt to the preference of the other, that is, the leader or the member. Some insisted that it is a leader's responsibility to understand their people and adapt to meet their preferred time-use. A member, who is also a leader of her own team, described her view:

'[I] don't think a team should change how they work for a leader. I think your leader needs to understand your specific workings and support you in that way.' (M07, Monochronic, Female)

Others viewed it as the member's responsibility to adapt to the needs of their manager, citing the extra pressure placed on a leader by virtue of their role and responsibility as motivation for members to make the shift. One member said:

' $[I]$ would think that because of their responsibilities, you know, we as a team should adjust also, we can adjust to it.' (M04, Polychronic/flexible, Female)

Thus, the members indicated the need to adjust to the timeuse preference of their leaders. Having established that these shifts in behaviour do indeed occur, the next question to ask was what triggers these changes.

\section{Forces driving the behavioural changes}

The findings showed that the process of initiating and effecting adjustment and adaptation occurs in differing ways across differing teams and no standard method stood out from the responses. Some, for example, held discussions with their leaders in order to reach a common understanding and engagement method.

Communicating about the differences is an effective means to proactively address them, as it also allows leaders and members to put in place a means to improve engagement. One monochronic member spoke of value of conversation with the leader:

'[W]e've had the discussion to say that, look, this is how I typically work. I like working on one thing, focus on it. But at the same time, I understand that you want things to be turned out a bit quicker but we need to get to a point where, you tell, whenever you brief me on something or you want something just at least give me an idea of how urgent this thing is and I know how to prioritise it.' (M08, Monochronic, Male)

Others identified drivers of change included conflict, change in leadership, urgency of tasks, as well as support and encouragement from a leader or peer. The fundamental motivation for change comes from a desire to deliver on the task at hand, as described by one leader:

' $[I]$ think getting out of one's comfort zone is never an easy thing, at any point. But the reality of the matter is that we know that life is uncomfortable, in any shape or form ... I try not to fixate in terms of what my preferences are, but in terms of the job at hand, and just get work done.' (L05, Monochronic, Female)

Some leaders and members saw the ability to move from monochronic to polychronic as a development need, either within themselves or expected from their teams. Part of improving this capability required investment from the leader, deliberate interactions, learning and teaching from both member and leader, as well as observing one another. One leader explained how he has engaged with a highly monochronic member to help her understand the need for interruptions in her daily work:

'[S]he doesn't mind that because the multiple engagements and meetings and other topics satisfy her general sense of curiosity in wanting to learn ... She just realises that these are placeholders to fulfil the task at a later stage.' (L07, Monochronic/flexible, Male)

Experience emerged as a further enabler to moving to polychronic behaviour; as individuals gained more experience in a certain role, their competence improved and they could then move to handling multiple tasks simultaneously. For monochronics, once members have had time to build up confidence and competence within the tasks they are performing, they find it easier to move away from their natural preference. One monochronic leader said:

' $[I]$ think a lot of my experience in the bank and working environment actually helped me to become the person that I am not normally at home, in terms of handling more than one thing, because at home I am actually a perfectionist, that is why I start one thing and finish it, I will not move on to other stuff. But at work, it's completely different, I can handle more than one thing.' (L04, Monochronic/flexible, Male)

\section{The impact of behavioural shifts on individuals}

The behavioural shifts described by the respondents in this study bore impact on the individuals adapting on an emotional level. Some leaders and members were able to describe not only their own feelings about the shifts being adopted, but the responses of others as well. One leader spoke of his monochronic members who were forced to engage in polychronic behaviours:

'[T] he only frustration from these personalities that prefer to have these limited amounts of things at a time is that they are not people who are comfortable with having engagement as a normal part of their day. So that they find it emotionally taxing for them to have to do these multiple engagements on a regular basis.' (L07, Monochronic/flexible, Male) 
TABLE 2: Key findings on manifestations, impact and adaptation of time preference. \begin{tabular}{lll}
\hline $\begin{array}{l}\text { Manifestation of time-use } \\
\text { preferences }\end{array}$ & $\begin{array}{l}\text { Impact on LMX } \\
\text { differentiation }\end{array}$ & $\begin{array}{l}\text { Adaptations of leaders and } \\
\text { members }\end{array}$ \\
\hline
\end{tabular} preferences

Monochronic individuals do Leaders find it easier to Leaders and members not want to be interrupted build and maintain adapt their time-use whilst focused on a task. relationships with behaviour to meet the Leaders tend to exhibit polychronic individuals needs of one another: polychronic behaviour in a in a polychronic development need. polychronic context, environment. regardless of preference.

Individuals associate time-use preference with personal attributes like introversion, personality profile and gender.

Management of expectations and of stakeholders is vital when engaging in polychronic behaviour. Coping mechanisms are used to manage the need to behave differently to preference. An underlying need to deliver drives required time-use behaviour.

Changes in behaviour can be triggered by change in leadership, conflict or communication and requires a shared vision.

Shifting to polychronic behaviour has an emotiona impact on monochronic individuals: stress, frustration, anxiety.

The majority of interviewees reported that shifting from a monochronic preference to polychronic behaviour took a toll on them emotionally, using words such as 'overwhelming', 'frustrating', 'stressful' and 'anxiety'.

The findings showed that there is much more to be learned in this field, and that time-use preference is a facet that deserves considerable attention in research and literature. Table 2 summarises the key findings as described here.

\section{Discussion}

\section{Outline of the results}

We have made several discoveries through this research. Firstly, time-use preference and behavioural differences manifest in the workplace in ways that are visible and can be articulated by leaders and members alike. We found clear examples of monochronic and polychronic preferences, both within interviewees themselves and as observed in their co-workers. We found associations between time-use preference and other personality or demographic traits, thus confirming previous suppositions that polychronicity is trait-like (Kirchberg \& Roe, 2015). Individuals described the coping mechanisms they employ to manage the need to work with individuals with opposing preferences to their own.

Secondly, we found that time-use preference differences impact the quality of the dyadic relationship between leader and member. Leaders were able to identify the preferences of their members and had put tools in place to manage these where they presented challenges. Leaders generally found it easier to work with polychronics, who were viewed as more adaptable and requiring less micro-management. Interviewees also voiced the need to manage upwards, as well as to tightly manage stakeholders within a polychronic environment, to ensure expectations are aligned. Underlying this theme is a need to deliver and perform; leaders felt that individuals' preferred ways of working must come second to a required outcome and that deadlines must be met regardless of how the work is performed.

Thirdly, we found that members and leaders adapt to one another and to the environment they are working in, shifting away from their own preference to a way of working, that is, more aligned to business requirements.

This suggested temporal entrainment or synchronisation of behaviour (Sandra \& Nandram, 2017). We found that both leaders and members made these adjustments and that opinions of who should adapt to whom varied through the data. Several forces drive these changes, ranging from the environment to a change in leadership, a conflict or as a result of a conversation. Implemented adaptations had an emotional impact on individuals, with monochronic members expressing stress, frustration and anxiety arising from exhibiting polychronic behaviours.

This study contributes to an understanding of time-use preference and its intersection with LMX. The contribution is significant given the increasingly multicultural, diverse nature of organisations and that implicit differences in individual's behaviour and preferences are often misunderstood, negatively impacting relationships (Conte et al., 1999). It addresses the need to understand how organisations manage tensions based on temporal differences (Bansal et al., 2019). Quality exchanges are a crucial enabler to individual and thus organisational performance (Martin et al., 2016). It is vital to understand the factors influencing differentiation in exchanges in order to better manage these underlying differences between individuals, which manifest themselves in very real ways within the organisational context. The dyadic relationships between leaders and members are not uniform (Dansereau et al., 1975) and the varying quality of these relationships can have an impact on workplace outcomes (Martin et al., 2018). This study offers insight into the role of time-use preference as a characteristic of individual behaviour (Capdeferro et al., 2014) in influencing the varying quality of relationships at the dyadic level.

We conclude that the manifestation of time-use preferences cannot be ignored. This means that leaders and members should be cognisant not only of their own behaviours and preferences, but also those of their colleagues, in order to manage the impact they will have on their relationships. This research takes us one step closer by contributing time-use preference as one explanation for differentiations in dyadic relationships, which should be further studied. We have also identified the adaptations that leaders and members make to adjust to one another's preferences, adding to the body of knowledge regarding relationship exchanges.

Figure 2 depicts our proposed framework of the dynamics of time-use preference-based relational entrainment. Our findings suggest that temporal choice results from individual factors and performance requirements.

Moreover, based on dyadic relational factors and related management of relationships, members and leaders adapt their temporal choices to suit one another. Several factors, such as communication or urgency, drive the adaptation, and 


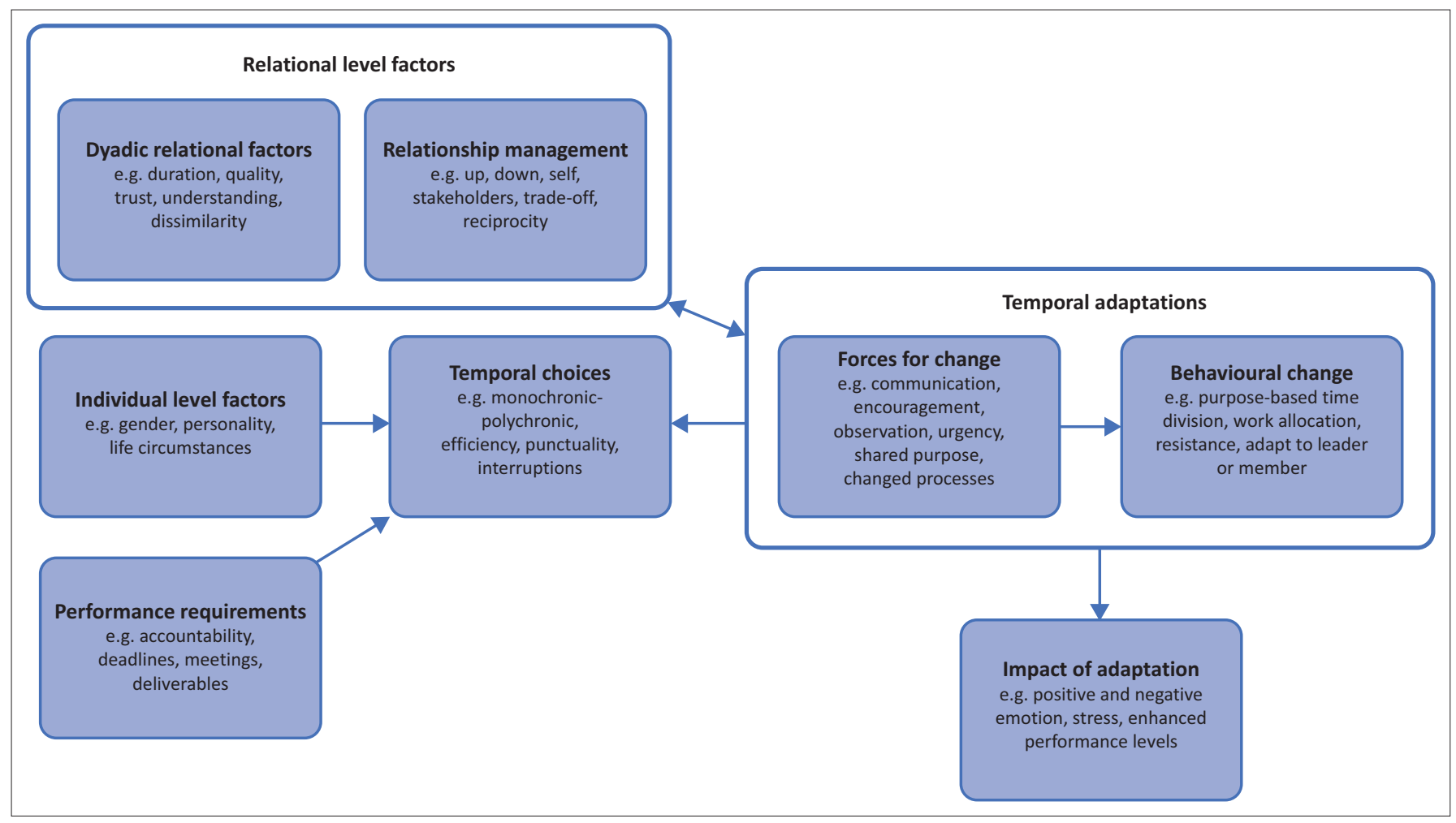

FIGURE 2: Dynamic process of time-use preference-based relational entrainment.

this manifests in changed behaviour. The outcome of these temporal adaptations are new temporal choices, but also unintended emotional impact and stress.

\section{Practical implications}

For leaders and members to navigate time-use preference differences, we provide some practical guidelines.

Firstly, leaders and members should discuss time-use preferences and understand their own preference as well as those of their colleagues. A common lexicon to describe 'the silent language' (Hall, 1977) may help to build understanding and empathy before conflict arises and relationships are damaged.

Secondly, time-use preference influences this relationship differentiation. To aid in creating a higher-quality relationship, time-use behaviours should be convergent within a team and align to the environment. Leaders can drive these behavioural adaptations through creating a shared purpose for the team, which encompasses a way of working, albeit with some flexibility. Leaders can put structures and processes in place to support their members as they diverge from their natural preference to behave in a more cohesive manner with the team and environment. Members need to be motivated to make the shifts by understanding the shared purpose and the positive effects that adaptations can have. In addition, members need to proactively communicate with their leaders regarding their deliverables, to build trust and to give themselves space to work in their preferred style when possible.
Thirdly, leaders must be cognisant of their role in influencing shifts in behaviour. Leaders have the power to help their monochronic members develop polychronic behaviours, should members have a flexible mindset and a willingness to adapt. Leaders have control of many of the forces, which drive time-use behavioural shifts.

Recognising the importance of management to ensure control, efficiency and accountability, Kniffin, Detert and Leroy (2020) observed that leadership is preferred over management when members work under time pressure. However, forcing a behavioural shift in a strongly monochronic member can have negative implications, resulting in poor quality work or undesirable emotional impact on the members. Leaders need to strike a balance between pushing members to grow and creating a supportive environment where they can play to their strengths.

\section{Limitations and recommendations}

Time-use preference is a rich and diverse construct. This study focused mainly on the multi-tasking aspect of polychronicity, thus future research should explore other aspects of the construct such as punctuality and a preference for scheduling. This study was scoped to one organisation, which provided a polychronic context, therefore future research should test this conceptual model in a monochronic context, as well as perform comparisons across different organisations. The mechanisms through which time-use preferences and other preferences impact LMX differentiation are still unknown and therefore further personal and contextual factors may be examined in the terms of time-use 
preferences and the quality of relational exchanges. In addition, it was expected that an element of culture would emerge in this study, given the multicultural nature of the organisation and literature reviewed on the topic (Brislin \& Kim, 2003).

Whilst this did not emerge from the research, a future study could focus more on cultural aspects to attempt to draw this out or to eliminate it as a cultural dimension. More insight into personality traits and polychronicity would be useful in contributing to the body of knowledge on relational exchanges.

\section{Conclusion}

The construct of time-use preference is pervasive but silent within organisations, yet this study has shown that despite its silence, it manifests within teams and affects individuals and relationships. It also influences behaviour, with leaders and members adapting to one another. Factors which affect the leader-member relationship become vital to understand as the quality of relationship impacts directly on work outcomes and strategic management. By contributing knowledge of time-use preferences in relational exchanges, this article also provides tools to help leaders and members overcome the negative impact these unspoken differences may have. By simply being aware of and addressing time-use preference with their members, leaders can mitigate potential negative impacts of diverging preferences and improve the quality of LMX.

\section{Acknowledgements}

The authors would like to thank the financial institution and the interviewees for their participation.

\section{Competing interests}

The authors declare that they have no financial or personal relationship(s), which may have inappropriately influenced them in writing this article.

\section{Authors' contributions}

A.G. conducted the research and wrote the first draft of the article. C.L. supervised the research and co-authored the later versions of the article.

\section{Ethical considerations}

Gordon Institute of Business Science, MBA Research Ethics Committee. Ethical clearance was obtained through the ethics committee of Gordon Institute of Business Science, MBA Research Ethics Committee prior to conducting the research. We assured participants of confidentiality and anonymity and posed non-threatening questions for research integrity.

\section{Funding information}

This research received no specific grant from any funding agency in the public, commercial or not-for-profit sectors.

\section{Data availability}

Data are available in a separate repository upon request from the authors.

\section{Disclaimer}

The views expressed in this article are those of the authors and not the formal views of the affiliated academic institution.

\section{References}

Adams, S.J.M., \& Van Eerde, W. (2010). Time use in Spain: Is polychronicity a cultural phenomenon? Journal of Managerial Psychology, 25(7), 764-776. https://doi. org/10.1108/02683941011075292

Agndal, H., \& Nilsson, U. (2019). The fast and the furious: The role of entrainment in controlled inter-organizational relationship transformation. Management Accounting Research, 43(1), 15-28. https://doi.org/10.1016/j.mar.2018.09.001

Bansal, P., Reinecke, J., Suddaby, R., \& Langley, A. (2019). Special issue of strategic organization 'temporal work: The strategic organization of time', Strategic Organization, 17(1), 145-149. https://doi.org/10.1177/1476127018824166

Bluedorn, A.C. (2002). The human organization of time: Temporal realities and experience. Stanford, CA: Stanford University Press.

Bluedorn, A.C., \& Jaussi, K.S. (2008). Leaders, followers, and time. The Leadership Quarterly, 19(6), 654-668. https://doi.org/10.1016/j.leaqua.2008.09.006

Bluedorn, A.C., Kalliath, T.J., Strube, M.J., \& Martin, G.D. (1999). Polychronicity and the Inventory of Polychronic Values (IPV): The development of an instrument to measure a fundamental dimension of organizational culture. Journal of Manageria Psychology, 14(3/4), 205-231. https://doi.org/10.1108/02683949910263747

Braun, V., \& Clarke, V. (2006). Using thematic analysis in psychology. Qualitative Research in Psychology, 3(2), 77-101. https://doi.org/10.1191/1478088706qp063oa

Brislin, R.W., \& Kim, E.S. (2003). Cultural Diversity in people's understanding and uses of time. Applied Psychology: An International Review, 52(3), 363-382. https://doi. org/10.1111/1464-0597.00140

Bryant, A., \& Charmaz, K. (2019). The Sage handbook of current developments in grounded theory. London: Sage.

Capdeferro, N., Romero, M., \& Barberà, E. (2014). Polychronicity: Review of the literature and a new configuration for the study of this hidden dimension of online learning. Distance Education, 35(3), 294-310. https://doi.org/10.1080/01587919. 2015.955249

Conte, J.M., \& Gintoft, J.N. (2005). Polychronicity, big five personality dimensions, and sales performance. Human Performance, 18(4), 427-444. https://doi. org/10.1207/s15327043hup1804_8

Conte, J.M., Rizzuto, T.E., \& Steiner, D.D. (1999). A construct-oriented analysis of individual-level polychronicity. Journal of Managerial Psychology, 14(3/4), 269-288. https://doi.org/10.1108/02683949910263837

Creswell, J.W., \& Creswell, J.D. (2017). Research design: Qualitative, quantitative, and mixed methods approaches. Thousand Oaks, CA: Sage.

Creswell, J.W., \& Miller, D.L. (2000). Determining validity in qualitative inquiry. Theory into Practice, 39(3), 124-130. https://doi.org/10.1207/s15430421tip3903_2

Cropanzano, R., Dasborough, M.T., \& Weiss, H.M. (2017). Affective events and the development of leader-member exchange. Academy of Management Review, 42(2), 233-258. https://doi.org/10.5465/amr.2014.0384

Dansereau, F., Graen, G., \& Haga, W. (1975). A vertical dyad linkage approach to leadership within formal organizations: A longitudinal investigation of the role making process. Organizational Behavior and Human Performance, 13(1), 46-78. https://doi.org/10.1016/0030-5073(75)90005-7

Dille, T., Söderlund, J., \& Clegg, S. (2018). Temporal conditioning and the dynamics of inter-institutional projects. International Journal of Project Management, 36(5), 673-686. https://doi.org/10.1016/j.ijproman.2018.03.007

Dirks, K.T., \& Ferrin, D.L. (2002). Trust in leadership: Meta-analytic findings and implications for research and practice. Journal of Applied Psychology, 87(4) 611-628. https://doi.org/10.1037/0021-9010.87.4.611

Dulebohn, J.H., Bommer, W.H., Liden, R.C., Brouer, R.L., \& Ferris, G.R. (2012). A metaanalysis of antecedents and consequences of leader-member exchange: Integrating the past with an eye toward the future. Journal of Management 38(6), 1715-1759. https://doi.org/10.1177/0149206311415280

Eisenhardt, K.M., \& Graebner, M.E. (2007). Theory building from cases: Opportunities and challenges. Academy of Management Journal, 50(1), 25-32. https://doi. org/10.5465/amj.2007.24160888

Fein, E.C., Benea, D., Idzadikhah, Z., \& Tziner, A. (2020). The security to lead: A systematic review of leader and follower attachment styles and leader-member exchange. European Journal of Work \& Organizational Psychology, 29(1), 106-125. https://doi.org/10.1080/1359432X.2019.1696774

Fournier, C., Weeks, W.A., Blocker, C.P., \& Chonko, L.B. (2013). Polychronicity and scheduling's role in reducing role stress and enhancing sales performance. Journa of Personal Selling \& Sales Management, 33(2), 197-210. https://doi.org/10.2753/ PSS0885-3134330204 
Gibbs, G.R. (2018). Analyzing qualitative data (2nd edn.). London: Sage.

Glaser, B.G., \& Strauss, A.L. (2009). The discovery of grounded theory: Strategies for qualitative research (4th edn.). New Brunswick, NJ: Aldine.

Graen, G.B., \& Uhl-Bien, M. (1995). Relationship-based approach to leadership Development of leader-member exchange (LMX) theory of leadership over 25 years: Applying a multi-level multi-domain perspective part of the management sciences and quantitative methods commons. The Leadership Quarterly, 6(2), 219-247. https://doi.org/10.1016/1048-9843(95)90036-5

Hall, E.T. (1977). Beyond culture. New York, NY: Anchor Books.

Hampden-Turner, C., \& Trompenaars, F. (2011). Riding the waves of culture: Understanding diversity in global business. London: Hachette.

Harvey, S. (2015). When accuracy isn't everything. Group \& Organization Management, 40(1), 35-61. https://doi.org/10.1177/1059601114561786

Henderson, D.J., Liden, R.C., Glibkowski, B.C., \& Chaudhry, A. (2009). LMX differentiation: A multilevel review and examination of its antecedents and outcomes. Leadership Quarterly, 20(4), 517-534. https://doi.org/10.1016/j.leaqua.2009.04.003

Hofstede, G., \& Minkov, M. (2010). Long- versus short-term orientation: New perspectives. Asia Pacific Business Review, 16(4), 493-504. https://doi. org/10.1080/13602381003637609.

Johnson, L. (2017). Interviewing. In L. Johnson (Ed.), Community-based qualitative research (pp. 80-100). Thousand Oaks, California: SAGE Publications, Inc. https:// www-doi-org.uplib.idm.oclc.org/10.4135/9781071802809.

Kantrowitz, T.M., Grelle, D.M., Beaty, J.C., \& Wolf, M.B. (2012). Time is money: Polychronicity as a predictor of performance across job levels. Human Performance, 25(2), 114-137. https://doi.org/10.1080/08959285.2012.658926

Kirchberg, D.M., Roe, R.A., \& Van Eerde, W. (2015). Polychronicity and multitasking: A diary study at work. Human Performance, 28(2), 112-136. https://doi.org/ A diary study at work. Human
$10.1080 / 08959285.2014 .976706$

Kniffin, K.M., Detert, J.R., \& Leroy, H.L. (2020). On leading and managing: Synonyms or separate (and unequal)? Academy of Management Discoveries, 6(4), 544-571. https://doi.org/10.5465/amd.2018.0227

Landy, F.J., Rastegary, H., Thayer, J., \& Colvin, C. (1991). Time urgency: The construct and its measurement. Journal of Applied Psychology, 76(5), 644-657. https://doi. org/10.1037/0021-9010.76.5.644

Le Blanc, P.M., \& González-Romá, V. (2012). A team level investigation of the relationship between leader-member exchange (LMX) differentiation, and commitment and performance. The Leadership Quarterly, 23(3), 534-544. https://doi.org/10.1016/j.leaqua.2011.12.006

Liden, R.C., Erdogan, B., Wayne, S.J., \& Sparrowe, R.T. (2006). Leader-member exchange, differentiation, and task interdependence: Implications for individua and group performance. Journal of Organizational Behavior, 27(6), 723-746. https://doi.org/10.1002/job.409

Liden, R.C., \& Maslyn, J.M. (1998). Multidimensionality of leader-member exchange: An empirical assessment through scale development. Journal of Management, 24(1), 43-72. https://doi.org/10.1016/S0149-2063(99)80053-1
Macan, T.H., Shahani, C., Dipboye, R.L., \& Phillips, A.P. (1990). College students' time management: Correlations with academic performance and stress. Journal of management: Correlations with academic performance and stress. Journal of Educational
82.4 .760

Martin, R., Guillaume, Y., Thomas, G., Lee, A., \& Epitropaki, O. (2016). Leader-member exchange (LMX) and performance: A meta-analytic review. Personnel Psychology 69(1), 67-121. https://doi.org/10.1111/peps.12100

Martin, R., Thomas, G., Legood, A., \& Dello Russo, S. (2018). Leader-member exchange (LMX) differentiation and work outcomes: Conceptual clarification and critical review. Journal of Organizational Behavior, 39(2), 151-168. https://doi. org/10.1002/job.2202

Mittal, R., \& Bienstock, J. (2020). Leadership styles and polychronicity: Impact on work-home boundaries and life satisfaction. Academy of Management Annual Meeting Proceedings, 2020(1), 1. https://doi.org//10.5465/AMBPP.2020. 13479abstract

Morse, J.M. (2015). Critical analysis of strategies for determining rigor in qualitative inquiry. Qualitative Health Research, 25(9), 1212-1222. https://doi.org/10.1177/ 1049732315588501

Murphy, S.E., \& Ensher, E.A. (1999). The effects of leader and subordinate characteristics in the development of leader-member exchange quality. Journal of Applied Social Psychology, 29(7), 1371-1394. https://doi.org/10.1111/j.15591816.1999.tb00144.x

Nowack, K. (2016). About time: Individual temporal orientation, time succession, and cognitive capacities. Berlin: Humboldt-Universität zu Berlin.

Persing, D.L. (1999). Managing in polychronic times. Journal of Managerial Psychology, 14(5/6), 358. https://doi.org/10.1108/02683949910277111

Poposki, E.M., \& Oswald, F.L. (2010). The multitasking preference inventory: Toward an improved measure of individual differences in polychronicity. Human Performance, 23(3), 247-264. https://doi.org/10.1080/08959285.2010. 487843

Sandra, D., \& Nandram, S. (2017). Spiritual leadership as a driver of organizational entrainment. Proceedings of the 13th European Conference on Management Leadership and Governance, London (pp. 444-451). Reading, UK: Academic Conferences and Publishing International Limited.

Saunders, M.N.K., \& Lewis, P. (2017). Doing research in business and management. Harlow: Pearson Education Limited.

Schein, E.H. (1991). Organizational culture and leadership. San Francisco, CA: Jossey-Bass.

Tanskanen, J., Mäkelä, L., \& Viitala, R. (2019). Linking managerial coaching and leadermember exchange on work engagement and performance. Journal of Happiness Studies, 20(4), 1217-1240. https://doi.org/10.1007/s10902-018-9996-9

Van Dick, R., Van Knippenberg, D., Hägele, S., Guillaume, Y.R.F., \& Brodbeck, F.C. (2008). Group diversity and group identification: The moderating role of diversity beliefs. Human Relations, 61(10), 1463-1492. https://doi.org/10.1177/00187267 08095711 